\title{
Strengths and weaknesses of using elastic numerical modelling in mine design at the Callie underground mine
}

\author{
HF Arbi Newmont Mining Corporation, Australia \\ K Doumis Newmont Mining Corporation, Australia \\ N Dalton Newmont Mining Corporation, Australia
}

\begin{abstract}
Site geotechnical engineers are often reliant on elastic numerical modelling to assist with mine design and the selection of appropriate stoping sequences. Although plastic numerical models are often preferred, site engineers do not have access, or the ability, to use these codes. Hence, three-dimensional elasto-plastic analyses are not viable at most sites. The challenge for the site engineers is to use the available tools most effectively, and present the results in a way that most clearly communicates the mine design requirements.

A first step is to establish a mine design criteria, which should not be confused with failure criteria. Mine design criteria correlate observed conditions with modelled stress states at a specific location. An effective mine design criterion then enables the assessment of probable future ground conditions on modelled stress states. Many design criteria could be used concurrently on a single mine site, as different failure mechanisms cannot be assessed with the same criterion.

Comparing actual conditions or measurements with modelled stress states is the only way to establish a correlation that could be generalised into a design criterion. During the back analysis process, the actual response of the rock mass is recorded and categorised with a damage classification system and compared to different modelling result parameters. Different correlations are evaluated, and the criterion with the most consistent performance selected to make predictions of future ground conditions.
\end{abstract}

This paper shares case studies where design criteria were successfully used at the Callie underground mine, and discusses the potential application areas for future evaluations.

Keywords: back analysis of elastic numerical modelling

\section{Introduction}

The Callie underground mine (CUG) is situated in the Tanami desert of the Northern Territory, $530 \mathrm{~km}$ north west of Alice Springs. The mine has been in operation since 1998 and has produced an excess of 4 million ounces since production started. The current production rate is 2.5 million tonnes per annum, producing an excess of 400,000 ounces.

CUG consists of several orebodies, with the Auron and Lantin orebodies currently the active production areas. The ongoing exploration activities have also found new orebodies and extensions of the existing orebodies. Each of these orebodies will be divided into smaller mining blocks with potentially different mining geometries and sequences. Geotechnical assessment is required to evaluate the stress impact from the mining geometry and sequence, and anticipate the ground response.

The biggest challenge for site geotechnical engineers is to perform sensible analysis in a limited time frame, and present the results in a simple and effective manner to other departments. Three-dimensional (3D) elastic numerical modelling is the most effective tool for geotechnical engineers to assist with the evaluation of mining geometry and sequence. Correlating the modelled stress states to a measurable condition is an important aspect to simply and clearly communicate the predictions and recommendations to others. 
Comparing actual conditions or measurements with modelled stress states is the only way to establish a correlation that could be generalised into a design criterion. During the back analysis process, the actual response of the rock mass is recorded and categorised with a damage classification system, and then compared to different modelling result parameters. Different correlations are evaluated, and the criterion with the most consistent performance is selected to make predictions of future ground conditions.

This paper shares case studies where design criteria were successfully used at CUG, and discusses the potential application areas for future evaluations.

\section{Design criteria}

Mine design criteria could be established from two different stress field approaches; far-field stresses and near field stresses. The far field approach considers the far field stresses, while the near field approach considers the near-boundary stresses (Basson \& Dunn 2009). Figure 1, in conjunction with the following sub-sections, describes the differences of these approaches with an example of access development relative to a stoping void.
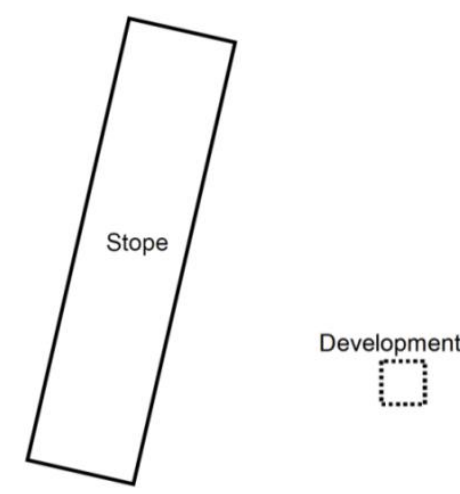

Figure 1 Section view of a stoping void and access development to illustrate different design criteria approaches

\subsection{Far field stress approach}

With the far field stress approach, the model does not require to explicitly include the development excavation in the simulation. The condition, or the stability, of the access development is predicted based on the stress condition at the proposed location, without the explicit presence of the proposed excavation in the model. Multiple locations along the development can be evaluated in a single model, without having to explicitly model the development. This approach is simple and able to provide quick guidelines for site geotechnical engineers to determine the most appropriate location of development or permanent infrastructure from the production area. This approach is suitable in the initial stage of a geotechnical review and quick to adjust for different scenarios. Two mine design criteria that are suitable when using the far-field stress approach are:

- Major principal stress $\left(\sigma_{1}\right)$.

Expected condition in excavations is related to the major principal stress magnitude $\left(\sigma_{1}\right)$. The following empirical rules apply to the field stress of brittle quartzite in South African Gold mines (Ozbay et al. 1995).

○ $\frac{1}{3} U C S_{\text {intact }}$ - start of rock mass damage.

- $\frac{1}{2} U C S_{\text {intact }}$ - substantial damage.

○ $\frac{2}{3} U C S_{\text {intact }}$ - uncontrolled damage. 
- Rockwall condition factor RCF (COMRO 1988).

$$
R C F=\frac{\text { Stress }_{\text {rockmass }}}{\text { Strength }_{\text {rock mass }}}=\frac{3 \sigma_{1}-\sigma_{3}}{F \sigma_{c}}
$$

where:

$$
\begin{aligned}
\sigma_{c}= & \text { UCS of intact rock. } \\
F= & \text { a downgrading factor from the intact rock to the rock mass strength. } \\
R C F= & \text { a far-field design criterion only, as the stress change from the development is accounted } \\
& \text { by the Kirsch equation. } \\
\sigma_{1}, \sigma_{3}= & \text { maximum and minimum stresses in the plane of the excavation cross section. }
\end{aligned}
$$

\subsection{Near field stress approach}

The near field stress approach is a more detailed approach where the tunnel is explicitly modelled and the tunnel condition evaluated based on the stresses close to the boundary of the tunnel. In order to evaluate the best position of access development from stoping voids, several models with explicitly removed development must be constructed to assess different development locations, and the results compared. Substantial effort is required, especially when assessing several development locations.

Mine design criteria derived from $\sigma_{1}$ versus $\sigma_{3}$ charts are widely used in the near stress field approach. This paper will focus on the process to establish mine design criteria from $\sigma_{1}$ versus $\sigma_{3}$ charts.

\subsubsection{Design criteria derived from $\sigma_{1}$ versus $\sigma_{3}$ chart}

General steps or methodologies to obtain mine design criteria with near field stress approach are outlined in

\begin{tabular}{|c|c|c|c|c|c|}
\hline Category A & Category B & Category C & Category D & Category E & Category F \\
\hline $\begin{array}{l}\text { No visible } \\
\text { damage }\end{array}$ & $\begin{array}{l}\text { Minor } \\
\text { damage } \\
\text { (spalling) }\end{array}$ & $\begin{array}{l}\text { Moderate } \\
\text { damage (spalling) }\end{array}$ & $\begin{array}{l}\text { Significant damage } \\
\text { to excavations }\end{array}$ & $\begin{array}{l}\text { Severe damage to } \\
\text { excavations }\end{array}$ & $\begin{array}{l}\text { Extreme damage } \\
\text { to excavations. } \\
\text { Opening collapse }\end{array}$ \\
\hline $\begin{array}{l}0 \mathrm{~m} \\
\text { indicated } \\
\text { depth of } \\
\text { damage }\end{array}$ & $\begin{array}{l}0 \text { to } 0.2 \mathrm{~m} \\
\text { indicated } \\
\text { depth of } \\
\text { damage }\end{array}$ & $\begin{array}{l}\text { Indication of } \\
\text { damage/loosenin } \\
\mathrm{g} \text { to up to } 0.5 \mathrm{~m} \\
\text { depth into wall or } \\
\text { backs }\end{array}$ & $\begin{array}{l}\text { Indication of } \\
\text { damage/loosening } \\
\text { to a depth up to } \\
1.5 \mathrm{~m} \text { depth into } \\
\text { wall or backs }\end{array}$ & $\begin{array}{l}\text { Indication of } \\
\text { damage/loosening } \\
\text { to a depth greater } \\
\text { than } 1.5 \mathrm{~m} \text { but } \\
\text { less than } 4.0 \mathrm{~m}\end{array}$ & $\begin{array}{l}\text { Indication of } \\
\text { damage/loosening } \\
\text { to a depth greater } \\
\text { than } 4.0 \mathrm{~m}\end{array}$ \\
\hline $\begin{array}{l}0 \% \text { of drive } \\
\text { profile } \\
\text { affected }\end{array}$ & $\begin{array}{l}<10 \% \text { of drive } \\
\text { profile } \\
\text { affected }\end{array}$ & $\begin{array}{l}10-50 \% \text { of profile } \\
\text { affected }\end{array}$ & $\begin{array}{l}>50 \% \text { of profile } \\
\text { affected }\end{array}$ & $\begin{array}{l}>80 \% \text { of profile } \\
\text { affected }\end{array}$ & $\begin{array}{l}100 \% \text { of profile } \\
\text { affected }\end{array}$ \\
\hline $\begin{array}{l}\text { Easily } \\
\text { controlled } \\
\text { with minimal } \\
\text { support, } \\
\text { e.g. split sets }\end{array}$ & $\begin{array}{l}\text { Easily } \\
\text { controlled } \\
\text { with minimal } \\
\text { support, } \\
\text { e.g. split sets }\end{array}$ & $\begin{array}{l}\text { Minor } \\
\text { rehabilitation } \\
\text { required in high } \\
\text { utilisation } \\
\text { excavations }\end{array}$ & $\begin{array}{l}\text { Significant } \\
\text { rehabilitation } \\
\text { required to } \\
\text { maintain safe } \\
\text { access }\end{array}$ & $\begin{array}{l}\text { Limit of } \\
\text { rehabilitation with } \\
\text { conventional } \\
\text { support }\end{array}$ & $\begin{array}{l}\text { Access not } \\
\text { advisable, beyond } \\
\text { rehabilitation }\end{array}$ \\
\hline
\end{tabular}
the following sections.

\subsubsection{Underground observation}

Inspect the underground excavations to determine the typical response of the rock mass to different stress environments. Table 1 shows examples of rock mass responses to different stress environments.

Table 1 Example of categories of rock mass responses to different stress environments (Sandy et al. 2010) 


\subsubsection{Construct and run a numerical model}

During the back analysis process, the observation areas are built into the model. The back analysis model should include any excavations that will affect the stress state in the observation area, and also include the mining sequence when the observed damage occurred. Construct grids at the observation area to calculate the $\sigma_{1}$ and $\sigma_{3}$ values close to the excavation boundary where the observations were made. It is important to use the same modelling parameters for back analysis and forward modelling. For the example, the model in back analysis and the model for forward modelling must use the same rock mass parameter, in situ stress and control model parameter (i.e. grid size).

\subsubsection{Tabulate result and obtain design criteria}

Use the back analysis model to get multiple $\sigma_{1}$ and $\sigma_{3}$ values in each observation area. Record and tabulate these $\sigma_{1}$ and $\sigma_{3}$ values with the appropriate observation result. Plot the results on a $\sigma_{1}$ versus $\sigma_{3}$ chart to obtain a mine design criterion.

The design criteria approach uses the Mohr-Coulomb failure criterion formula in Equation (2):

$$
\sigma_{1}=\sigma_{C}+q \sigma_{3}
$$

where:

$$
q=\tan (\psi)=\frac{1+\sin (\phi)}{1-\sin (\phi)}
$$

$$
\begin{aligned}
& \sigma_{c}=\text { rock mass strength. } \\
& q \quad=\text { strengthening factor. } \\
& \psi \quad=\text { obtained from } \sigma_{1} \text { versus } \sigma_{3} \text { charts. } \\
& \phi \quad=\text { friction angle of the material. } \\
& \sigma_{1}=\text { major principal stress. } \\
& \sigma_{3}=\text { minor principal stress. }
\end{aligned}
$$

The proposed mine design criterion then can be utilised to calculate a Factor of Safety (FOS) or using the following equations:

$$
F O S=\frac{\text { Capacity }}{\text { Demand }}=\frac{\text { Strength }_{\text {rockmass }}}{\text { Stress }_{\text {rock mass }}}
$$

For mine design criterion developed in the chart at Figure 2, FOS simply indicate that failure is likely to occur when FOS is less than one and conversely, failure is not likely to occur when FOS exceeds a value of one. 


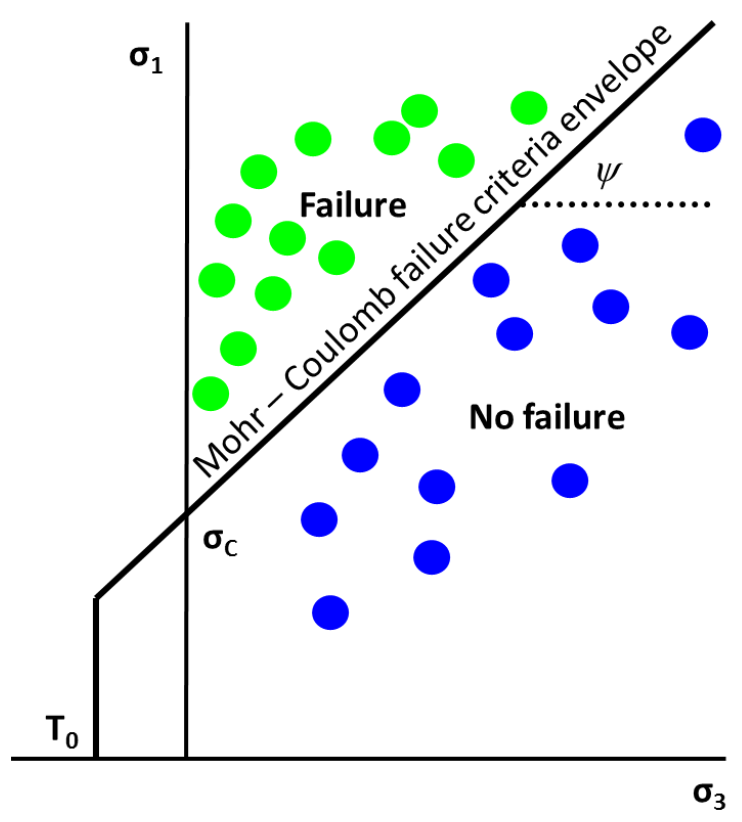

Figure 2 Mohr-Coulomb failure criterion in $\sigma_{1}$ and $\sigma_{3}$ space

\subsubsection{Test observations against the design criterion}

Map3D version 65 (Wiles 2016) has the capability to plot and visualise the value from a formula, and it can also export the calculated grid values to other visualisation software packages such as GEM4D (Basson 2016b). Furthermore, it can use the proposed mine design criterion, and calculate the FOS values, and visualise on a grid plane in Map3D or as an iso-surface in GEM4D. GEM4D also allows for the creation of heat-maps of the values on the excavation surfaces.

The reliability of the proposed mine design criterion should be continuously reviewed as new data becomes available. Once the initial mine design criterion correlates well with the observed rock mass response, it could be applied in forward analysis.

\section{Design criteria for the Callie underground mine}

Site geotechnical engineers at CUG followed the method previously explained to obtain mine specific design criteria derived from a $\sigma_{1}$ versus $\sigma_{3}$ chart. The observations of stress induced rock mass damage and the study to establish a mine design criterion were started in 2010 by site geotechnical engineers (Graf \& Basson 2010). The most recent external study of stress related damage at CUG was carried out by Australian Mining Consultants (AMC) in 2014 (Watson 2014), and was based on the new in situ stress values and orientations. At the time of the study, only one location of observable stress damage was found during their underground visit. A recommendation from the AMC report was to perform further underground observations to identify new areas of stress induced damage and further develop reliable mine design criteria.

\subsection{Underground observation}

\subsubsection{Initial observations}

At the time of the AMC report in 2014, CUG had only experienced limited stress induced rock mass damage. The observed damage in one of the access drives in the 180 development level was the most useful information for the back analysis process conducted by AMC. Based on the results of modelling, the induced stress from the extraction in one of the stope was the likely cause of damage in the observation area. Further damage was expected to occur when mining stopes in the proximity was conducted. 


\subsubsection{Further observations}

The site geotechnical engineers performed further inspections in the Lantin and Auron mining areas to establish a mine design criterion for each of these mining areas. Stress related damage was difficult to find in the non-production area, therefore, the geotechnical team focused their damage inspection on the production areas. The geotechnical team discovered more stress related damage in the abutment areas of stoping, especially in the drives with an east-west orientation. Most of these damage areas occurred in the lower part of the northern walls (approximately $1.5 \mathrm{~m}$ above floor level), which was not supported by mesh or bolts. Observed stress damage consists largely of wall buckling and spalling. The typical depth of damage extends approximately $0.2 \mathrm{~m}$ into the backs and walls. The damage was effectively controlled with scaling, mesh and split sets. Based on the damage categories in Table 1, CUG currently largely experiences the minor damage of Category B. Figures 3, 4 and 5 show the observation areas and the location of observed stress related damage mostly located in the abutments of stoping voids.

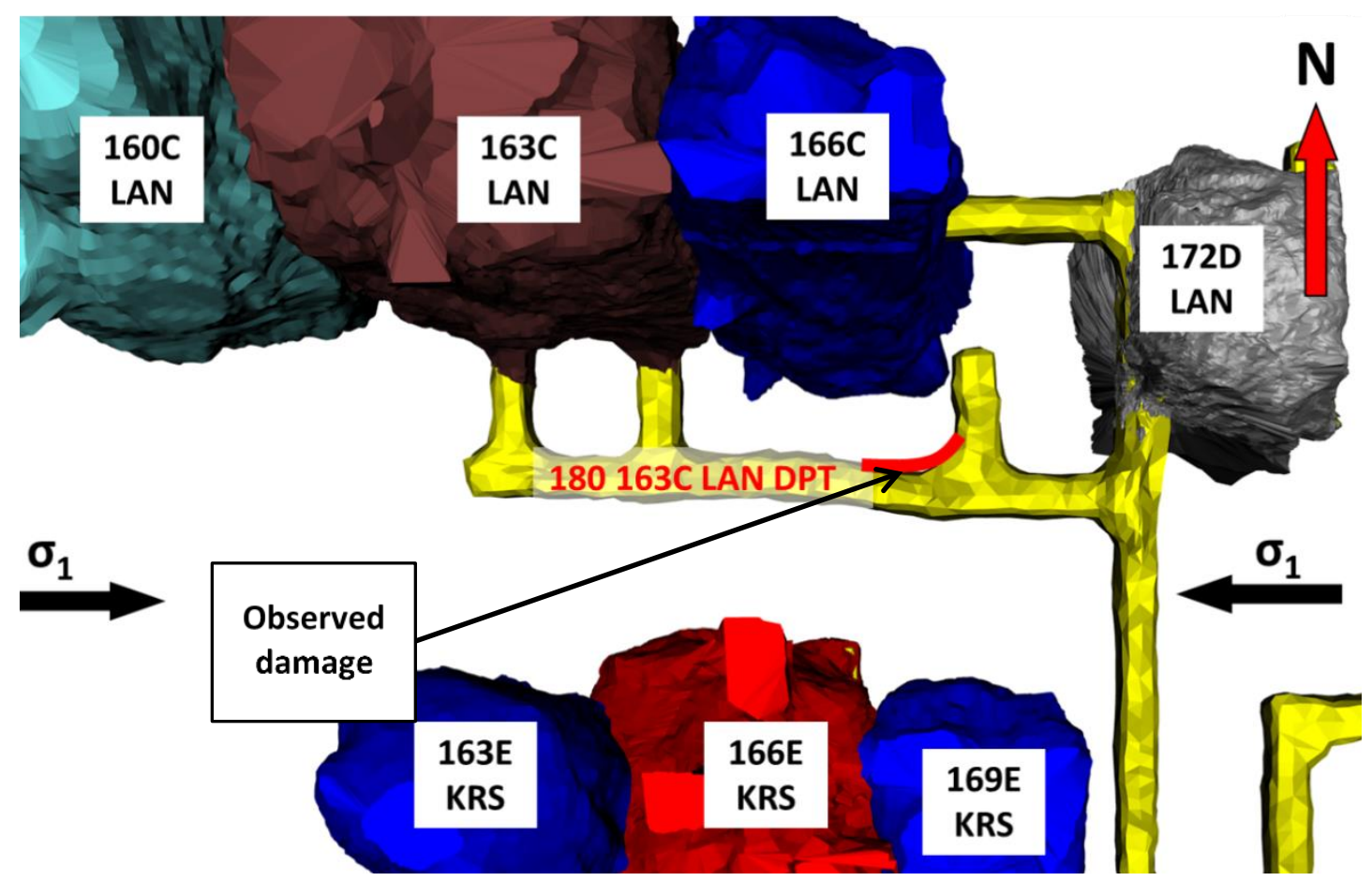

Figure 3 Location of stress induced damage of Lantin orebody in 180 development level 


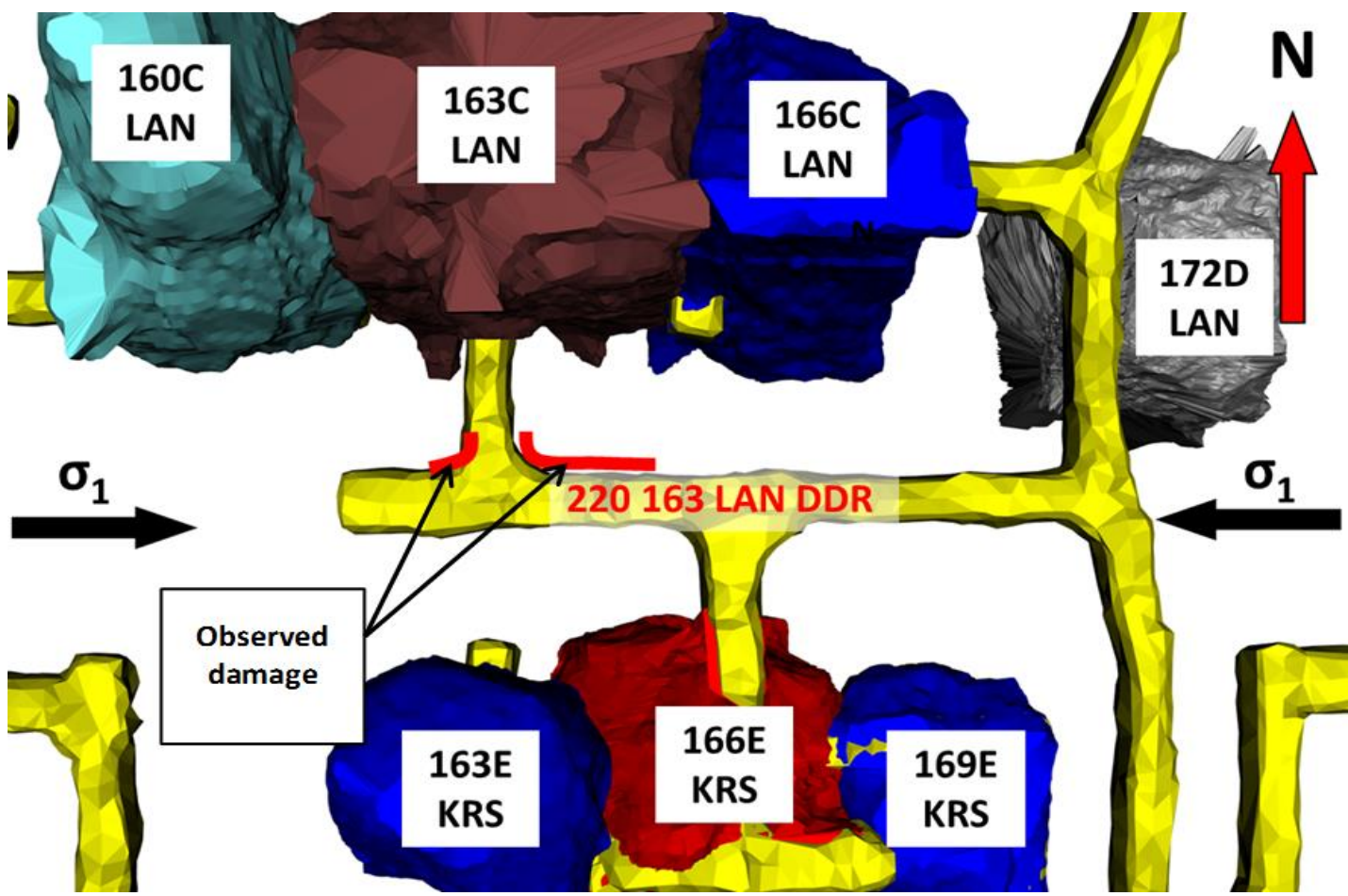

Figure 4 Location of stress induced damage of Lantin orebody in 220 development level

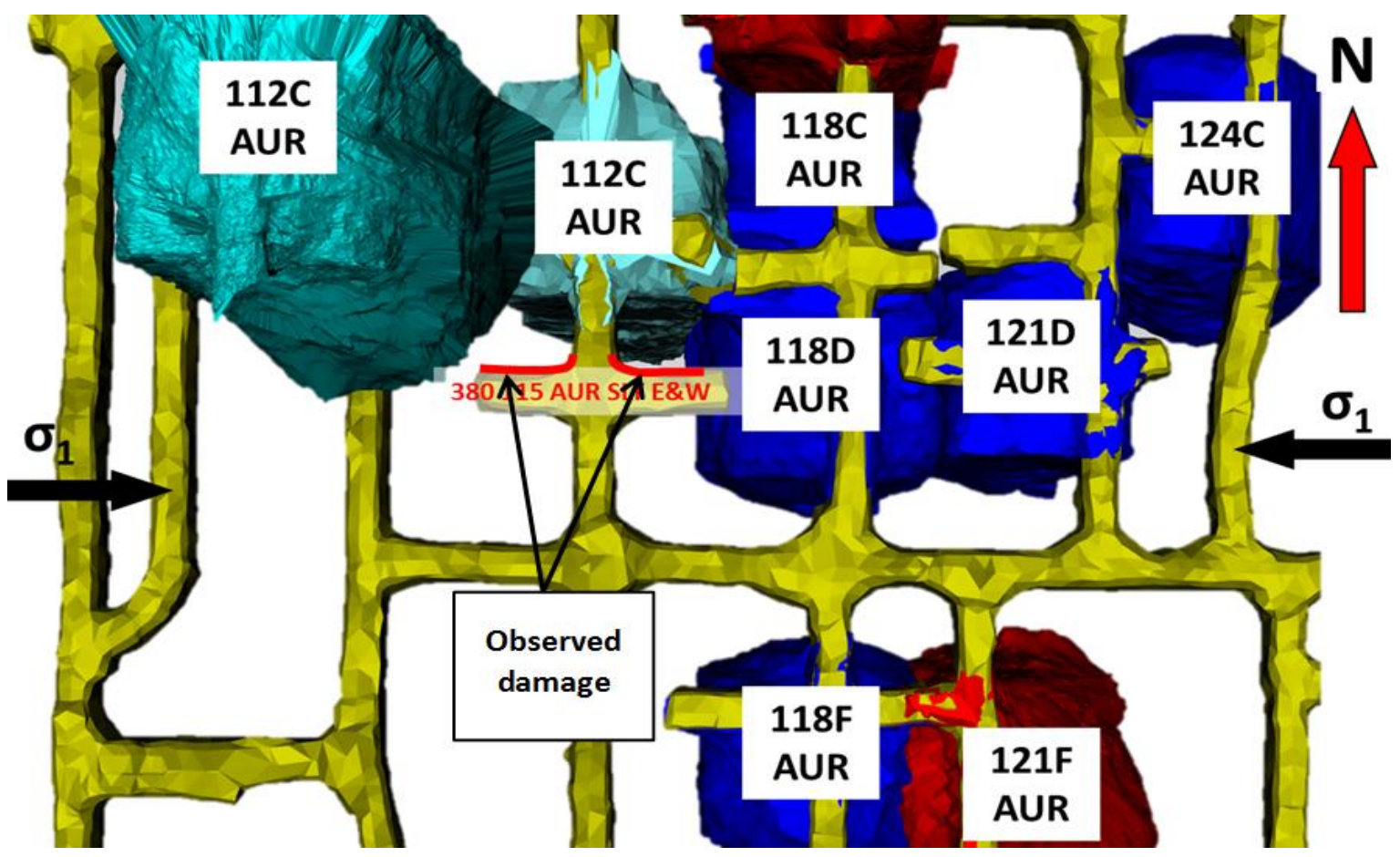

Figure 5 Location of stress induced damage of Auron orebody in 380 development level

\subsubsection{Observation of the area without stress damage in Auron and Lantin orebody}

A mine design criterion should be able to predict rock behaviour transitions, for example when the rock mass transitioning from 'no stress damage' to 'stress damage' is likely to occur. A distinct boundary between 'no damage' and 'rock mass damage' cannot be obtained from a $\sigma_{1}$ versus $\sigma_{3}$ chart if all of the observations are only undertaken in the areas with stress related damage occurred. Readings have to be taken from both undamaged and damaged areas. 


\subsection{Construct and run numerical model}

The primary inputs for the numerical modelling of the back analysis process are the excavations of the observation area, rock mass properties and in situ stress of the mine. The excavations where the observations were made are constructed in the numerical model. The model also includes the stope sequences before and after the damage occurred. Only the excavations that are expected to impact the stress state at the observation area are modelled to reduce the model size.

\subsection{Tabulate develop mine design criteria for each mining area}

The value of major principal stress $\left(\sigma_{1}\right)$ and minor principal stress $\left(\sigma_{3}\right)$ for each observation are tabulated with an assigned category of rock mass response. The two data populations from the Lantin and Auron mining areas were tabulated separately, as the rock mass condition is different in each orebody. The ground conditions from these two areas were expected to cause a difference in rock mass response to stress. The tabulated data were then plotted on two separate $\sigma_{1}$ versus $\sigma_{3}$ graphs for Lantin and Auron. The tabulated data can also be plotted in the software FailureCriteria (Basson 2016a), which assists to define a mine design criterion. Figure 6 shows the mine design criteria applicable for the Auron orebody and Figure 7 is a mine design criterion for the Lantin orebody. Each of these mine design criteria were then used to make predictions of rock mass response to different stress conditions in the respective mining areas.
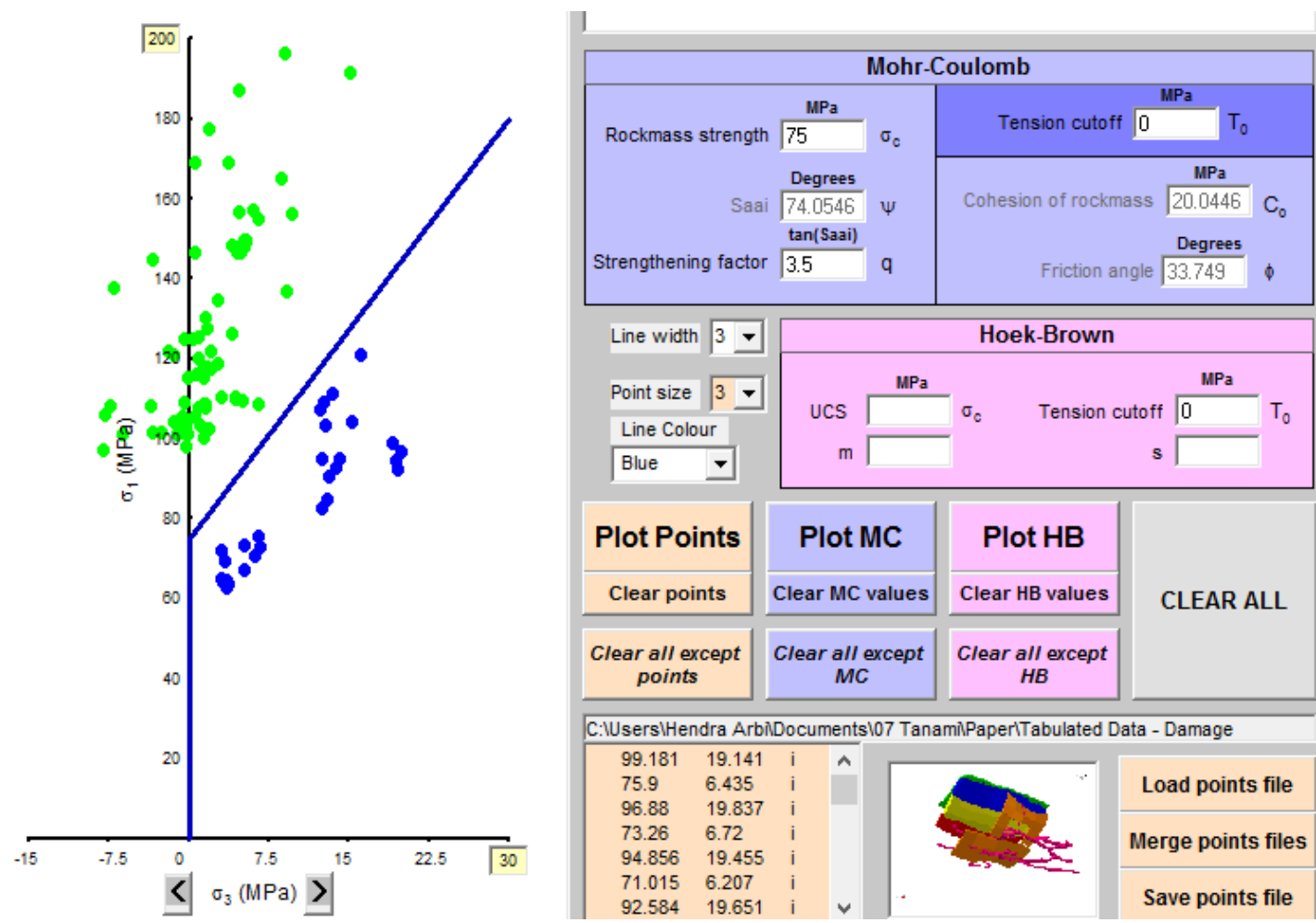

Figure 6 Mine design criteria for Auron orebody (blue dots for no damage, green dots for minor damage) 

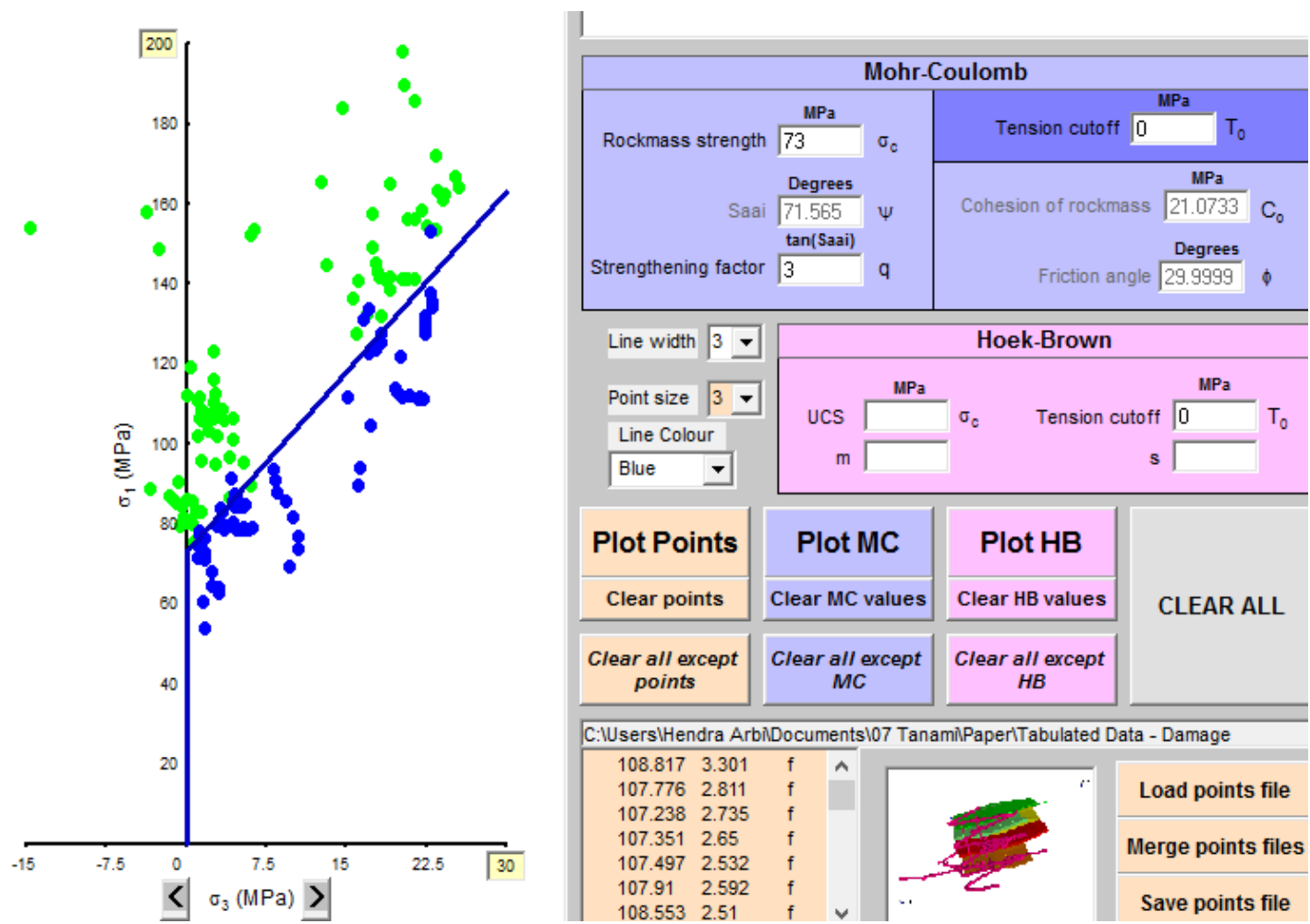

Figure 7 Mine design criteria for Lantin orebody (blue dots for no damage, green dots for minor damage)

The mine design criterion for Auron is $\sigma_{1}=3.5 \cdot \sigma_{3}+75 \mathrm{MPa}$ and the mine design criterion for Lantin is $\sigma_{1}=3.0 \cdot \sigma_{3}+73 \mathrm{MPa}$. These mine design criteria were utilised to calculate the FOS by using Equation (4).

\subsection{Test observation against design criteria}

The two mine design criteria for the Auron and Lantin orebody were then tested for accuracy and consistency. The test with Map3D was undertaken by plotting the values resulting from the equation of FOS, from the previous noted equations, into solution grids. This method is quick and straightforward, but with the limitation that it can only show 2D contours and thus only provide limited information from the area of interest.

Another way to test the mine design criteria was done with software GEM4D. Map3D has the capability to export the stress states from all the grids as a csv file. This file usually contains the coordinates of each grid point and selected parameters, in this case the $\sigma_{1}$ and $\sigma_{3}$ values. A new column can be added by opening the csv file in Excel and calculate the FOS at each coordinate point. GEM4D can then use this file to plot and represent the results as an iso-surface or triangulation heat-map. The result can be compared with the underground observations as shown in Figure 8. The proposed mine design criterion can also be used for forward modelling, if the result matches the underground observations. If they do not match, the mine design criteria must be revisited, and further tests and correlations undertaken, until a better mine design criterion is found. Figure 8 shows the proposed mine design criteria as a heat-map triangulation in GEM4D, and the results correlate well with the underground observations. 


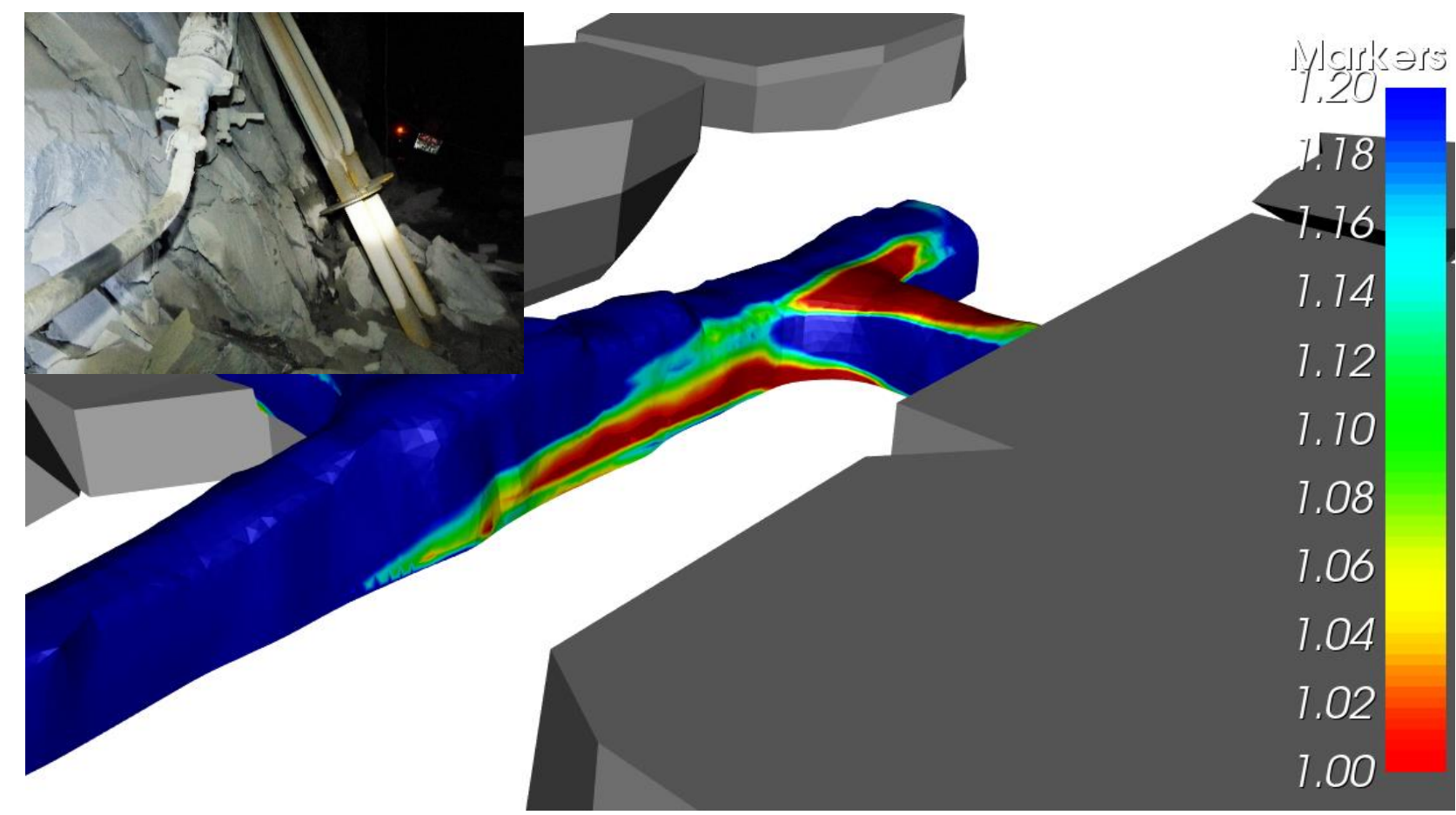

Figure 8 Good correlations between FOS less than 1 and damage observations in the Lantin orebody

\section{$4 \quad$ The utilisation of mine design criterion in the Callie underground mine}

Mine planning process in CUG consists of three stages; the long term, medium term, and short term plan. Medium term plan stage usually requires detailed analysis work to assess geotechnical concerns such as small or narrow pillars in the proximity of stopes, drawpoint that are too close to wide span development, re-entry into the high-stress areas, or proposed production in areas of high-stress.

Figure 9 shows a layout of the 260 development level in the Auron orebody with one small pillar and one critical drawpoint in the development level. This critical pillar and drawpoint cannot be eliminated due to a late discovery of additional ore in a previously mined area. The mine design criterion for the Auron orebody was used to predict the stability of a pillar and drawpoint, and determine the requirement of additional ground support. Based on the stress analysis, high stresses exist in the pillar and drawpoint. Using GEM4D to plot FOS values, as triangulation heat-maps enabled visualisation of potential stability issues within the pillar and drawpoint. Figure 10 shows the utilisation of GEM4D to plot FOS values as the iso-surface that can help to show the extent and the depth of the affected area in the pillar and drawpoint. Based on this model prediction, the geotechnical engineer was able to design additional ground support (cable bolts) with the intention of maintaining stability of these locations during stope production. 


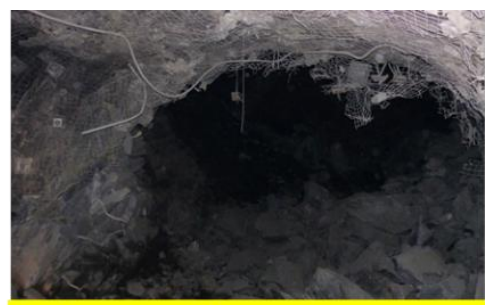

Failure in pillar and drawpoint

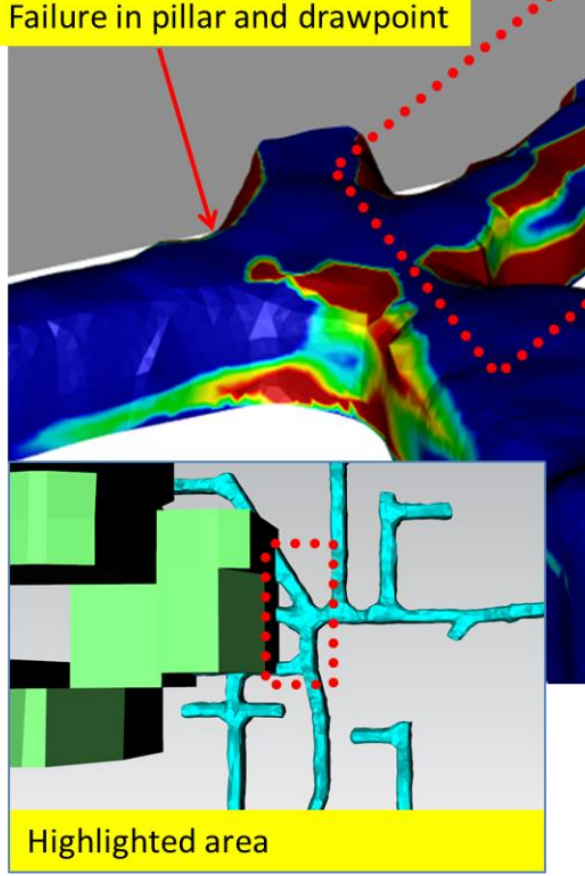

Figure 9 The prediction of stability of the pillar and drawpoint in 260 Auron development level by utilising a heat-map triangulation to plot the contours of FOS for the Auron orebody

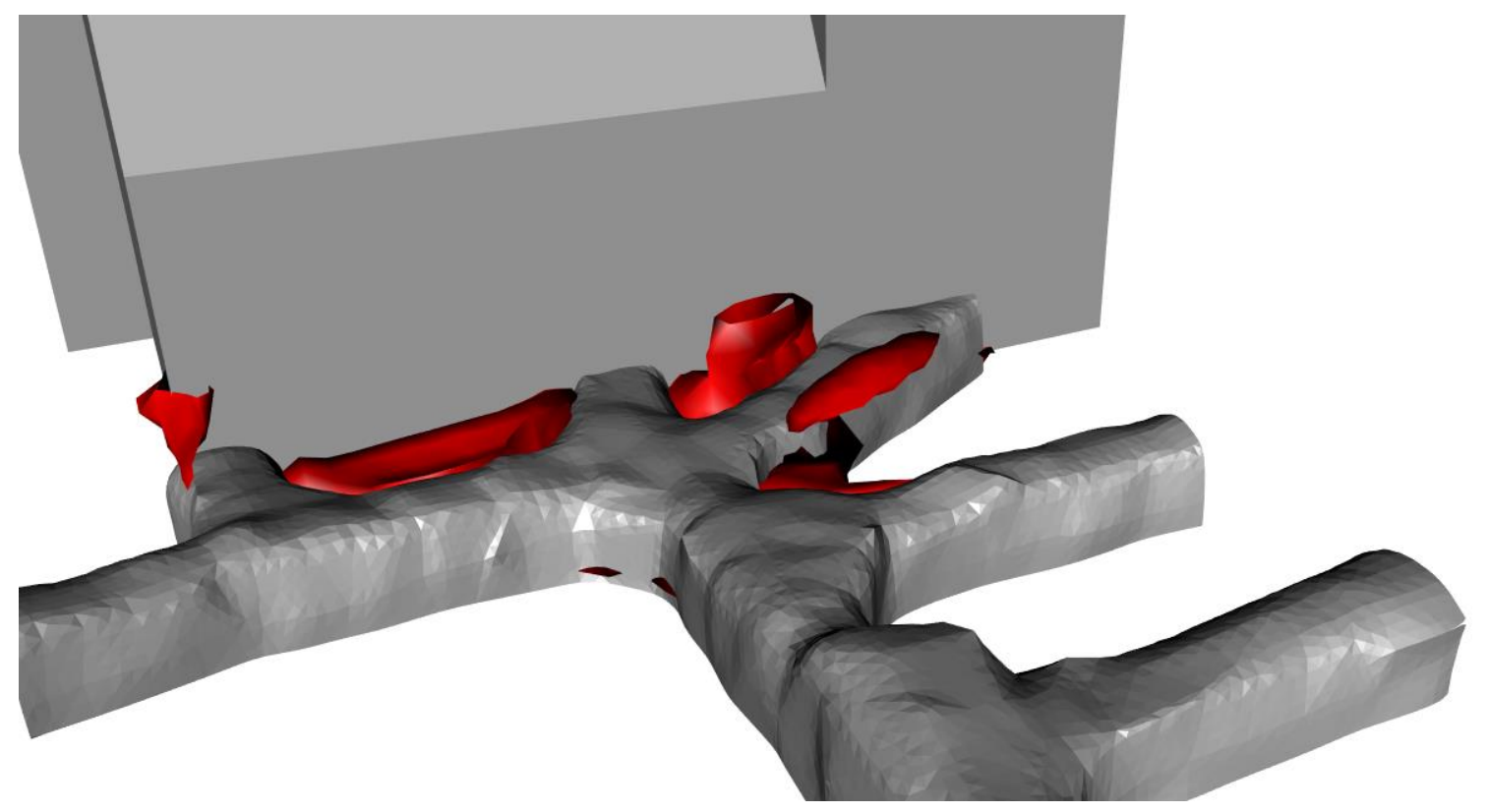

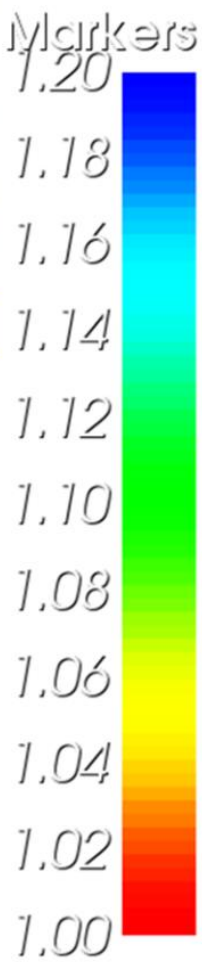

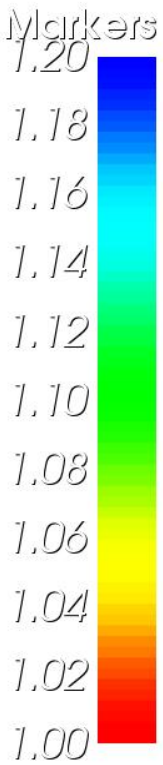

Figure 10 Iso-surface plot of FOS values in the pillar and drawpoint with GEM4D

During initial stope production, the pillar remained stable for a number of weeks. However, as stope extraction continued, the pillar failed, as the cable bolts installed were insufficient to effectively reinforce the pillar and drawpoint. As a result, stope production was ceased early. 
The established mine design criteria seems to predict potential failures well, and could indicate the location of the pillar and drawpoint that required additional ground support. However, this specific design criterion could not assist in the determination of the amount of additional ground support required to maintain stability. To address this, another mine design criterion is required that specifically targets this application.

\section{$5 \quad$ Concluding remarks}

Elastic numerical modelling does not provide a definitive answer to geotechnical modelling of stress induced damage. However, it can be utilised effectively, by site based geotechnical engineers, to simply and quickly construct and simulate a geotechnical model from a mine design with assigned sequences. Elastic numerical modelling does not need many parameters as inputs for modelling and, hence, less effort is required to calibrate the model.

Despite its simplicity and effectiveness, the elastic numerical modelling only provides limited outputs and information. The main output of the elastic numerical model is the stress values at a specified location, which is essentially meaningless if there is no suitable mine design criteria available. Some of the available empirical mine design criteria, such as major principal stress and rock wall condition factor, can be used as a conservative first pass approach. Continuous monitoring has to be undertaken to compare the modelled stress states with the actual rock mass response, which enable the site engineers to establish a correlation that can be generalised into a design criterion.

A cautious approach must be taken when using a mine design criterion, even if it has provided good indications of the expected rock mass response in the past. One mine design criteria may work for one type of failure mode, but it may not make an accurate prediction for another type of failure mode. Design criteria derived from $\sigma_{1}$ and $\sigma_{3}$ work well to predict rock mass damage caused by overstressing. But, the same design criterion may not work well to predict failures associated with the unconfinement of the rock mass. Thus, the site geotechnical engineer must first understand the failure mechanism, and then select the most appropriate design criterion.

\section{Acknowledgement}

The authors gratefully acknowledge the permission given by Newmont Asia Pacific and Newmont Tanami Operations, in particular, to publish this paper. The authors also highly appreciate the support from Frans Basson to review this paper. Support from the rest of the site geotechnical team, particularly Gaudence Lijaji is highly appreciated.

\section{References}

Basson, FRP 2016a, FailureCriteria, BasRock Software for Geotechs, Perth, Western Australia, http://www.basrock.com Basson, FRP 2016b, GEM4D, BasRock Software for Geotechs, Perth, Western Australia, http://www.basrock.net Basson, FRP \& Dunn, MJ 2009, Numerical Modelling Guidelines for Underground Mine, Internal Newmont Report, September. COMRO 1988, An Industry Guide to Methods and Amelioration the Hazards of Rockburst and Rockfalls, 2nd edn, Chamber of Mines Research Organisation, South Africa.

Graf, CC \& Basson, FRP 2010, 'Managing stress and ground condition changes with increasing depth at Callie underground mine', Second Australasian Ground Control in Mining Conference.

Ozbay, MU, Ryder, JA \& Jager, AJ 1995, 'The design of pillar systems as practiced in shallow hard-rock tabular mines in South Africa', Journal of the South African Institute of Mining and Metallurgy, vol 95, pp. 7-18.

Sandy, M, Sharrock, G, Albrecht, J \& Vakili, A 2010, 'Managing the transition from low stress to high stress condition', Second Australasian Ground Control in Mining Conference, The Australasian Institute of Mining and Metallurgy, Carlton South.

Watson, 0 2014, Tanami Production Expansion Geotechnical Study, Internal Newmont Report, November.

Wiles, T 2016, Map3D, version 65, Map3D International Ltd, http://www.map3d.com 